\title{
Data report: testing and deployment of the new APCT-3 tool to determine in situ temperatures while piston coring ${ }^{1}$
}

\author{
Martin Heesemann, ${ }^{2}$ Heinrich Villinger, ${ }^{2}$ Andrew T. Fisher, ${ }^{3}$ Anne M. Tréhu, ${ }^{4}$ and Steffen White ${ }^{5}$
}

\section{Chapter contents}

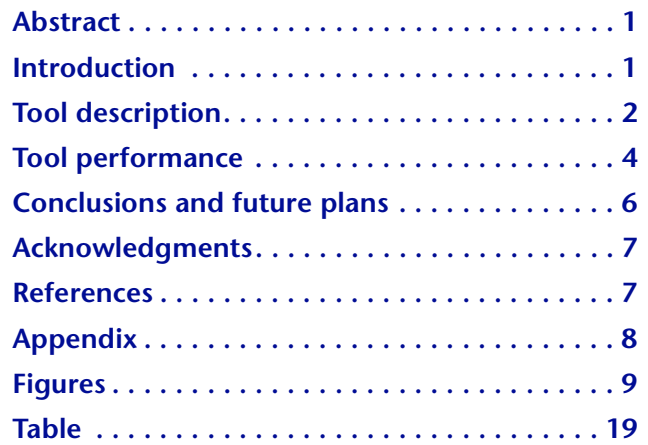

${ }^{1}$ Heesemann, M., Villinger, H., Fisher, A.T., Tréhu, A.M., and White, S., 2006. Data report: testing and deployment of the new APCT-3 tool to determine in situ temperatures while piston coring. In Riedel, M., Collett, T.S., Malone, M.J., and the Expedition 311 Scientists. Proc. IODP, 311: Washington, DC (Integrated Ocean Drilling Program Management International, Inc.). doi:10.2204/

iodp.proc.311.108.2006

2Universität Bremen, Department of Geosciences, Klagenfurter Strasse, 28359 Bremen, Germany. Correspondence author: heesema@unibremen.de

${ }^{3}$ Institute of Geophysics and Planetary Physics and Department of Earth Sciences, University of California, Santa Cruz, 1156 High Street, Santa Cruz CA 95064, USA.

${ }^{4}$ Expedition 311 Scientists' addresses. ${ }^{5}$ ANTARES Datensysteme, GmbHRudolf-DieselStrasse 6, 828816 Stuhr, Germany.

\section{Abstract}

During Integrated Ocean Drilling Program Expedition 311, the third-generation advanced piston corer temperature (APCT-3) tool, a new downhole tool to determine in situ formation temperatures while piston coring, was successfully tested and deployed for the first time. Its development was partly driven by the need to replace the advanced piston corer temperature tools, which were lost or damaged during many successful deployments over the last $15 \mathrm{y}$. Additionally, many important scientific problems require instruments having greater stability, accuracy, measurement frequency, and robustness than were available in the past. During all nine deployments during Expedition 311, the APCT-3 tool proved to be robust, reliable, and user-friendly regarding its mechanics, electronics, and operation software. In addition, the test deployments also provided temperature data that were important for achieving expedition objectives. Moreover, it was demonstrated that the APCT-3 tool is capable of measuring temperatures with a resolution and absolute accuracy (depending on careful calibration) of $\sim 1 \mathrm{mK}$ at a sampling interval of $1 \mathrm{~s}$, an improvement of about one order of magnitude compared to earlier instrumentation.

\section{Introduction}

Geothermal measurements provide important constraints on dynamic Earth processes; therefore, temperature was among the first downhole properties to be measured during the Deep Sea Drilling Project (DSDP) (Von Herzen and Maxwell, 1964). New tools were developed and modified during DSDP (Horai, 1985; Uyeda and Horai, 1982) and throughout the Ocean Drilling Program (ODP) (Davis et al., 1997; Fisher and Becker, 1993; Shipboard Scientific Party, 1992). Temperature measurements made during marine scientific drilling have been used to investigate heat transfer from the interior of Earth, oceanic lithosphere evolution, continental margin formation and subduction, and hotspot volcanism. In addition, these data have been used to examine processes associated with fluid flow and gas hydrate formation (e.g., Erikson et al., 1975; Hyndman et al., 1987; Pribnow et al., 2000). Undoubtedly, measurements of formation and fluid temperature will remain a high priority for downhole tool operations in the Integrated Ocean Drilling Program (IODP). 
During a 2004 IODP downhole tools workshop (Flemings et al., 2004), all participants agreed that precise downhole temperature measurements are essential for fulfilling the goals of the IODP Initial Science Plan (ISP) (Kappel and Adams, 2001) in all three of the primary research themes:

1. Deep biosphere and subseafloor ocean,

2. Environmental change processes and effects, and

3. Solid earth cycles and geodynamics.

With these goals in mind, researchers began developing the next generation of tools to measure subseafloor temperatures during routine piston coring operations. This data report summarizes results of the first in situ deployments of a new instrument that will help to achieve high-priority IODP goals.

Soon after development of the advanced piston corer (APC) during the late stages of DSDP, researchers developed a miniature sensor and logger package designed to fit in the APC cutting shoe to measure sediment temperatures as a core was taken (Horai and Von Herzen, 1985); the Advanced Piston Corer Temperature (APCT) tool. This tool allowed DSDP (and later, ODP) personnel to determine in situ temperatures within the undisturbed formation well ahead of the drilling bit without making a dedicated tool run. The APCT tool was first deployed during DSDP Leg 86 in 1984, and its use almost immediately became a routine part of drilling operations. Eight of these first-generation APCT tools were purchased by ODP at the start of the new program, but these tools became damaged over the years until none was left by the time of ODP Leg 117. It took several years to develop a replacement tool, but this was finally accomplished in time for ODP Leg 139 in 1991 (Shipboard Scientific Party, 1992). Ten of the second-generation APCT tools were purchased for ODP use and were deployed successfully during numerous expeditions over the next $12 \mathrm{y}$, through the end of ODP atsea operations.

By the end of ODP operations in 2003, most of the second-generation APCT tools had been lost or damaged, and several of the remaining tools had been serviced one or more times to repair damage. In addition, evaluation and comparison of in situ temperatures determined with the APCT tool and with other downhole tools (e.g., Shipboard Scientific Party, 1997) suggested that there was a need to reevaluate tool design, performance, calibration, and analysis procedures and to develop a third generation of APCT instrumentation. Funds for the development of a third-generation APCT system were secured by a joint German and U.S. team led by H.
Villinger (University of Bremen) and A. Fisher (University of California, Santa Cruz). In order to produce instruments with greater stability, accuracy, measurement frequency, and robustness than were available in the past, and in order to minimize development time and cost, the research team worked cooperatively on design of the new instruments with Fa. Antares (Stuhr, Germany), who had recently developed a miniaturized temperature data logger (MTL), also in cooperation with the University of Bremen (Pfender and Villinger, 2002; Jannasch et al., 2003). The design team consulted extensively with personnel from the U.S. operator for IODP to evaluate the design of the existing APCT coring shoe and related hardware in order to retain compatibility of system components with conventional coring operations. Work on the new system progressed during 2004-2005, and a prototype was made available in time for testing at sea during IODP Expedition 311. This third-generation APCT system is herein referred to as the APCT-3 tool.

The prototype APCT-3 tool was calibrated immediately before Expedition 311, as described below, and deployed nine times during the expedition. The calibrated APCT-3 prototype was also used to crosscheck calibration of previous generation APCT tools that were also used during the expedition. The primary scientific objective of Expedition 311 was to understand processes that control the distribution and amount of gas hydrate in the shallow sediments of the accretionary margin offshore Vancouver Island, northeastern Pacific Ocean (see the "Expedition 311 summary" chapter). Determination of subseafloor temperature is particularly important for achieving this objective because thermal conditions fundamentally control gas hydrate stability. Comparison of in situ temperatures, gas hydrate stability, and the depth of bottom-simulating reflectors (BSRs) determined with seismic reflection surveys will help to determine whether the gas hydrates found in the Expedition 311 region are in thermodynamic equilibrium. Thermal data collected during Expedition 311 are reported in individual site chapters along with preliminary determinations of in situ temperatures, thermal gradients, and heat flow derived from the data.

\section{Tool description}

Like the earlier generation APCT tools, the APCT-3 tool fits in an annular cavity in the APC cutting shoe (Fig. F1A). Tool electronics are arranged on a cylindrical frame; sensor and registration prongs extend close to the end and outside edge of the cutting shoe. During 
standard deployment, the APC inner core barrel is run to bottom on the coring wireline at the bottom of the borehole. Pump pressure is then applied to the drill pipe, which acts as a hydraulic accumulator. When pressure is great enough, it severs shear pins and strokes the inner core barrel $9.5 \mathrm{~m}$ into the sediment, well beyond the thermal influence of drilling operations. Following penetration, the core barrel is decoupled from the drill string and the APCT-3 is left stationary for 7-10 min. This allows part of the thermal disturbance associated with frictional heating of the penetration to decay. Finally, the coring shoe and core barrel are extracted from the formation and returned to the deck, where communication with the APCT-3 tool can be established and data are extracted for analysis.

The APCT-3 temperature logger consists of a temperature sensor and two circuit boards mounted on a cylindrical supporting frame (Fig. F1B). There is sufficient space on the electronics frame to hold a second electronics set, although this space is currently not used. It is anticipated that scientists may wish to develop additional measurement capabilities in the future using this space. At the base of the frame are two prongs that fit into index holes at the bottom of the annular cavity in the cutting shoe. These prongs help keep the electronics in place during deployment, and one of them houses the temperature sensor.

The sensor element for the APCT-3 tools is an aged, glass-encapsulated thermistor (Model YSI 55032). This thermistor has a high temperature coefficient ( $4 \%$ per degree change in temperature) across a wide usable temperature range from $-80^{\circ}$ to $+100^{\circ} \mathrm{C}$ (Fig. F2B) and can withstand temperatures as high as $200^{\circ} \mathrm{C}$ for brief periods. The lead wires of the sensor are soldered to the circuit board that holds the logger electronics. This board contains a microprocessor, a 16-bit analog to digital (A/D) converter, a real-time clock, and nonvolatile memory for as many as 65,000 readings.

Electrical power is supplied by two standard lithium batteries mounted on a second circuit board, which is easily serviceable and replaceable. The battery capacity allows at least 600,000 readings equaling continuous operation for $\sim 1$ week at a sampling rate of $1 \mathrm{~s}$. Even if there is a total loss of battery voltage, the recorded data are preserved in nonvolatile memory. The APCT-3 electronics can safely be operated at ambient temperatures from $-10^{\circ}$ to $60^{\circ} \mathrm{C}$. Nominal temperature resolution of the complete instrument is $\leq 2.5 \mathrm{mK}$ over a range from $-6^{\circ}$ to $+55^{\circ} \mathrm{C}$, and $\leq 1.0 \mathrm{mK}$ at temperatures $\leq 25^{\circ} \mathrm{C}$ (Fig. F2). This range should be adequate for the vast majority of shallow environments in which APC coring is likely to be attempted during IODP.

Communication with the APCT-3 temperature logger is accomplished using custom software (WinTemp) and an interface box that connects to the contact pins of the logger on one side (Fig. F1B) and to the RS-232 port (or universal serial bus [USB] port by adapter) of a personal computer (PC) running Microsoft Windows 2000/XP. WinTemp was originally developed for use with MTLs and provides a graphic interface for programming and data recovery. Using a logger setup dialog, it is possible to set the logger's real-time clock or synchronize it with the clock of the PC. The operator sets logging start date and time, logging duration, and a constant sample interval during deployment ranging from $1 \mathrm{~s}$ to $255 \mathrm{~min}$. The software also provides functionality to retrieve temperature data from the logger, clear the tool's memory, check battery voltage, and display real-time readings of digital counts, resistance, and apparent temperature.

After recovering data from a tool, WinTemp displays calculated temperatures in text format, and data can be saved in a binary file ( ${ }^{*}$.wtf), a WinTemp-specific format, or exported to an ASCII-format file ( ${ }^{*}$.dat). The latter file consists of a multiline header, which includes the logger identification number and columns of measurement dates, times, A/D converter readings, computed thermistor resistances, and computed temperatures. Computations of resistance and temperature are based on the information contained in a calibration file $\left({ }^{*}\right.$. wtc), which is assigned to an individual logger. Tool-specific calibration information is stored in the binary data files along with the logger readings.

Antares supplies calibration files with every delivered logger. The contents of these files are based on the specifications of the electronic components comprising the APCT-3 data logger and the resistance-temperature curves supplied by the manufacturer of the thermistors. These calibration files offer an absolute accuracy on the order of $\pm 0.1^{\circ} \mathrm{C}$, but considerably greater accuracy on the order of $\pm 0.001^{\circ}-0.002^{\circ} \mathrm{C}$ can be achieved through careful calibration and processing, as discussed below.

Once data are converted to temperatures using the calibration coefficients, additional processing is required to estimate undisturbed formation temperature. As with all penetrating subseafloor temperature measurement tools, a tool response function must be used to extrapolate observations (e.g., Bullard, 1954; Davis et al., 1997; Horai, 1985). This function depends on tool geometry, distribution of frictional heat generated during tool penetration, and thermal 
properties of the sediments and the tool. For conventional oceanic heat flux measurements the analytical $\mathrm{F}(\mathrm{a}, \mathrm{t})$ function is used as a reference for comparison with observations (Bullard, 1954; Carslaw and Jaeger, 1959). Use of the $F(a, t)$ function presumes, however, that the geometry of the probe is well described by a semi-infinite solid cylinder, which is not the case for the more complex geometry of the APCT-3 tool.

An analytical solution for a one-dimensional radial geometry was developed for the first-generation APCT tool (Horai, 1985), with a central cylinder of sediment, a ring of metal, and an infinite surrounding region of sediment. This approach, like that for a thin cylindrical probe, is based on the assumption that the tool behaves as if it extends vertically well away from the sensor and that heat transport following tool insertion is purely radial within a homogeneous medium. This approach was adapted for use in software having a graphical interface (TFit) that was developed as part of the second-generation APCT tool.

Decay curves are calculated for different sediment thermal conductivity values, and a curve is usually selected on the basis of independent observations of thermal conductivity from needle probe measurements on recovered core. It is common practice during processing to allow an arbitrary shift in time between modeled and measured decay curves so as to minimize the misfit between measured and modeled decay curves. This time shift is intended to correct for a series of nonideal behaviors, including incomplete knowledge of tool insertion time, finite time for insertion (possibly involving multiple frictional pulses), finite tool response time, incomplete thermal coupling between the sensor and the shoe, modification to sediment properties both inside and outside the tool, short-term advection immediately adjacent to the coring shoe, and nonhorizontal heat conduction.

As a practical matter, there is often considerable uncertainty in sediment thermal properties, including heterogeneity, immediately adjacent to the APC coring shoe, so the user must process data using a range of assumed sediment thermal conductivities in order to evaluate uncertainties. Even in the case of ideal tool response (i.e., no motion of shoe during temperature decay following the initial friction spike), it is not possible to use statistical-fit criteria to determine the effective thermal conductivity; essentially all decay curves can be made to fit the data, albeit on the basis of different time shifts. In cases where the decay curve is not ideal, it may be necessary to use only part of the record and different record segments may indicate different equilibrium temperatures. As a re- sult of these uncertainties, a range of extrapolated temperatures will be generated, and it is often not possible to determine the equilibrium temperature with uncertainties $<0.1^{\circ}-0.2^{\circ} \mathrm{C}$.

In addition, the geometry of the APC coring shoe is not one-dimensional and radial. The shoe is tapered at its front end, and the probe tip is located close to the front of the shoe (Fig. F1A). As a result, the measured temperature in the shoe may decay according to a function that differs from that derived for a onedimensional, radial analytical model. Additional deviations from the one-dimensional model may result from heterogeneities in sediment properties (natural or induced by tool penetration) and associated frictional heating or conduction of heat vertically along the coring shoe.

The complete APCT-3 project includes considerable modeling and analysis, much of which is still underway, to evaluate uncertainties in extrapolated temperatures and improve standard procedures. For the purposes of prototype testing during Expedition 311 and the results presented in this volume, we have used TFit software developed for the second-generation APCT tool. This allowed rapid analysis of available data and comparison with data collected using earlier tools. We will reanalyze Expedition 311 data later when the rest of APCT-3 modeling and software development is complete.

\section{Tool performance}

\section{Calibration}

The prototype APCT-3 tool was made available for use only a few days prior to the start of Expedition 311. Fortunately, there was time for calibration across a limited range of $1.5^{\circ}-9.5^{\circ} \mathrm{C}$. During calibration, the APCT-3 and a calibrated reference thermistor were submerged in a continuously stirred, cylindrical water bath $\sim 60 \mathrm{~cm}$ in diameter and $\sim 75 \mathrm{~cm}$ high. Calibration bath temperatures were maintained by competing cooling and heating systems controlled using the reference sensor. Temperatures measured with the reference sensor have absolute accuracy of better than $2 \mathrm{mK}$ and were recorded when the temperature in the tank was within a small window around each of five temperature values used for calibration. The limited temperature range of pre-Expedition 311 calibration resulted mainly from limitations in available time. A wider temperature range will be used for calibration of the production APCT-3 tools and prototype during the coming year.

There are two general ways to apply calibrations to APCT-3 temperature data. One way is to apply an ex- 
perimentally determined calibration to the exported ASCII data. Alternatively, one could also create new calibration files ( ${ }^{*}$.wtc) that are used by the WinTemp software. To do the latter, one must supply two pairs of $\mathrm{A} / \mathrm{D}$ converter readings, $x$ (digital counts), and corresponding resistances $R(\mathrm{Ohm})$ and three pairs of resistances and corresponding reference temperatures $T\left({ }^{\circ} \mathrm{C}\right)$. The $x-R$ pairs are used to identify the scale $m$ and the offset $b$ in the equation

$$
R=m(x+b) /(13,1071-[x+b]),
$$

which is used to compute resistances $R$ from logger readings $x$. Subsequently, the $R-T$ pairs are used to compute the coefficients $A_{\mathrm{i}}$ in a standard (Steinhart and Hart, 1968; Bennett, 1972) equation:

$$
1 / T=\mathrm{A}_{1}+\mathrm{A}_{2} \ln (R)+\mathrm{A}_{3} \ln ^{3}(R) .
$$

Note that although WinTemp requires entering reference temperatures in Celsius, computations in Equation E2 are done in Kelvin and $R$ is dimensionless (resistance divided by $1 \Omega$ ). This empirical equation is known to provide a good match to thermistor characteristics with a minimum number of free parameters. Figure F3 illustrates the ability of the Steinhart and Hart equation to reproduce the resistancetemperature characteristics of the selected thermistor (YSI 55032) across the APCT-3 measurement range with three reference temperatures $\left(-5^{\circ}, 25^{\circ}\right.$, and $55^{\circ} \mathrm{C}$ ). Temperatures predicted by the equation provide an accuracy of about $\pm 10 \mathrm{mK}$ with respect to the reference temperatures specified by the thermistor manufacturer. This accuracy is maintained during moderate extrapolation of a few degrees beyond the range of the reference points. It is, however, possible to improve the accuracy gained with the Steinhart and Hart equation by increasing the number of coefficients $\left(A_{\mathrm{i}}\right)$ or by reducing the calibration temperature range.

Figure F4A shows the calibration reference temperatures and respective APCT-3 temperatures, which were computed with the standard WinTemp calibration file. The differences between reference temperature and APCT-3 temperature range from about -37 $\mathrm{mK}$ at $1.5^{\circ} \mathrm{C}$ to $-29 \mathrm{mK}$ at $9.5^{\circ} \mathrm{C}$ (Fig. F4B, F4C). Linearly extrapolated over the whole measurement range from $-5^{\circ}$ to $55^{\circ} \mathrm{C}$, these differences range from -44 to $18 \mathrm{mK}$, respectively. Using an ad hoc approach, all APCT-3 temperature data shown in the site chapters of the Expedition 311 Proceedings of the Integrated Ocean Drilling Program were corrected by adding a constant offset of $30 \mathrm{mK}$. This approach is justified because the accuracy of undisturbed formation temperatures extrapolated by the TFit software is on the order of $\pm 0.1^{\circ} \mathrm{C}$. To take advantage of the APCT-3's enhanced resolution and accuracy in a new temperature extrapolation algorithm, however, a more sophisti- cated calibration approach will be developed for future use with the production APCT-3 tools.

Reference temperatures and resistances, computed using Equation E1 and the constants $b$ and $m$ provided by Antares, were used to determine optimized coefficients $A_{i}$ in Equation E2 (see Fig. F4D; Table T1). The resulting standard deviation of the differences between reference temperatures and APCT-3 temperatures of $0.6 \mathrm{mK}$ (Fig. F4E, F4F) is similar to the APCT-3's temperature resolution in the given temperature interval (Fig. F2). Numerous temperature data measured with MTLs testify (e.g., Heesemann et al., 2005) that this excellent signal to noise ratio is typically achieved by the Antares temperature logger electronics. As shown in Figure F5, small temperature undulations in the order of a few $\mathrm{mK}$ that occur while a temperature plateau is held in the calibration bath are resolved by the reference thermistor as well as the calibrated APCT-3 temperatures.

During rapid temperature changes, there is, however, a small apparent time lag between the APCT-3 temperature and the reference temperature resulting in increased temperature differences. For instance, this behavior causes the increased temperature differences during oscillations at the beginning of the temperature plateaus (cf. Figs. F4B, F5B). The time lag is caused by a somewhat greater response time for the APCT-3 electronics than for the reference sensor. This is not surprising since the APCT- 3 tool is placed inside a coring shoe having a large thermal mass, and there is an imperfect contact between the sensor and shoe, with heat sink compound used to fill the gap between the sensor prong and the index hole in the coring shoe.

The thermal time constant of the APCT- 3 tool in the coring shoe characterizes the response time of the temperature measurement system to an abrupt change in temperature. It is defined as the time that is required until the difference between the sensor temperature and the new ambient temperature is reduced to $1 / \mathrm{e}(\sim 36.8 \%)$ of the initial temperature difference. Typical time constants of glass-encapsulated thermistors in a well-stirred bath are $1.5 \mathrm{~s}$. During Expedition 311, experiments to estimate the time constant of the APCT-3 cutting shoe were performed. The tool was alternately submerged in containers with cold and warm water (cf. Fig. F6A). As shown in Figure F6B, the three resulting rapid transients were normalized so that the beginning of all transients equals one and all transients approach zero. Because of temperature variations in the containers, the steady-state temperature that is set to zero is not well defined. Nevertheless, it is possible to demonstrate that the APCT-3's time constant is on the order of $10 \mathrm{~s}$. 


\section{Results from Expedition 311}

During Expedition 311, nine APCT-3 deployments were performed in depths ranging from $\sim 30$ to $\sim 114$ meters below seafloor (mbsf). The overall data quality was excellent, and the standard TFit program was applied to all data measured at Sites U1325, U1326, and U1329. The three measurements at Site U1328 could not be processed because the deployments were disturbed by heave resulting from high seas. A complete temperature data set of a typical APCT-3 deployment (Core 311-U1325B-8H; $71.5 \mathrm{mbsf}$ ) is shown in Figure F7. Plots of all temperature data obtained during Expedition 311 are provided in their respective site chapters.

All important stages of an APCT-3 deployment cause a specific temperature signal, as recorded by the tool. These stages are as follows (numbers refer to parts of the example record in Fig. F7):

1. The APCT-3 is powered on in the laboratory.

2. The tool is lowered down the water column inside the drill string.

3. The tool stops at the mudline to establish a reference temperature for comparison with other downhole temperature. Since temperature variations during this stop are on the order of $0.1^{\circ} \mathrm{C}$ (Fig. F7B), this comparison does not replace a proper calibration of all tools but can help to reveal major intertool calibration problems.

4. The tool is lowered down the hole and briefly stopped at the bit near the bottom of the hole.

5. The coring shoe penetrates the formation in $\sim 5 \mathrm{~s}$ (Fig. F7C).

6. While the cutting shoe is held in the formation, the temperature peak, caused by frictional heating, decays slowly, and measured temperatures approach the undisturbed formation temperature. After 6-10 min, when sufficient data to allow extrapolation to undisturbed formation temperature is recorded, the decay with a remaining rate of $\sim 1 \mathrm{mK} / \mathrm{s}$ (Fig. F7D) is interrupted.

7. The tool is extracted from the formation, which also causes frictional heating (Fig. F7E).

8. The tool is once again stopped at the mudline.

9. The tool is carried up through the water column.

10. The tool is recovered on deck.

Figure F8A compares second-generation APCT data (Core 311-U1329C-11H; $95.6 \mathrm{mbsf}$ ) with APCT-3 data (Core 311-U1329C-13H; 114.6 mbsf). The APCT data exhibit a higher temperature peak caused by frictional heating in this example, probably as a result of penetrating sandier sediments, and there is a slower decay toward undisturbed formation temperature. Even though the temperature resolution as well as the time resolution of the APCT-3 surpasses the values of the older APCT by about one order of magnitude, both recorded decay curves appear to be well resolved. The derivative with respect to time of the APCT-3 data (Fig. F8B), however, reveals that temperature changes at the end of the decay curve are on the order of $1 \mathrm{mK} / \mathrm{s}$, matching the resolution of the APCT-3 tool.

As shown in Figure F9 a time resolution of $10 \mathrm{~s}$ is not sufficient to resolve the temperature changes of the heat pulse generated during the penetration of the probe. Figure F9A-F9C shows one temperature peak measured at a sampling interval of $1 \mathrm{~s}$ and three hypothetical measurements of the same data recorded using a sampling interval of $10 \mathrm{~s}$. Whereas time and magnitude of the temperature peak are well resolved in the APCT-3 measurement, the errors in estimated peak time and magnitude of the theoretical APCT measurements (e.g., Fig. F9B) are as much as $\sim 5 \mathrm{~s}$ and $\sim 20 \%$, respectively. It should be noted that early-time data (the first 20-60 s) following APCT insertion are typically omitted when estimating equilibrium formation temperatures; therefore, it is not clear whether the lack of temporal resolution common during many earlier deployments resulted in a systematic bias in calculated formation temperatures. Additional analysis of APCT-3 response will be completed as part of the ongoing project, but initial tests with the APCT- 3 tool give confidence as to the performance of the new electronics.

In order to cross-check the APCT-3 data with other downhole temperature data, we attempted to colocate measurements with the Davis Villinger Temperature Probe (DVTP). Unfortunately, these attempts failed because of bad weather conditions. Nevertheless, APCT-3 data are consistent with temperatures measured with other tools. For instance, the linear vertical temperature profile at Site U1329 (Fig. F10) provides additional qualitative verification of the data quality. Considering a mean thermal conductivity of $1.05 \mathrm{~W} /(\mathrm{m} \cdot \mathrm{K})$ (Fig. F10B), all estimated undisturbed formation temperatures are consistent with a conductive heat flux of $\sim 72 \mathrm{~mW} / \mathrm{m}^{2}$. Furthermore, the extrapolated seafloor temperature of $3.5^{\circ} \pm$ $0.5^{\circ} \mathrm{C}$ matches seawater temperatures of $3.5^{\circ} \pm 0.2^{\circ} \mathrm{C}$ (see the "Site U1329" chapter) at the water depth at Site U1329 $(950 \mathrm{~m})$. The seawater temperatures off Vancouver Island were measured within the World Ocean Circulation Experiment (WOCE) in September 1985 (WOCE Section P01) and in February 1994 (WOCE Section PR06).

\section{Conclusions and future plans}

A third-generation temperature tool, the APCT-3, has been developed for use during scientific ocean drill- 
ing when piston coring. The design of this new tool builds on the prior experience with previous temperature tools, most recently the APCT and the MTL. Consequently, the prototype described here proved to be very mature and only minor modifications are anticipated for the final production version, which should be available in the summer or fall of 2006 . Field tests during Expedition 311 and calibration tests prior to the expedition demonstrate that the APCT- 3 is a robust and reliable tool, with high and predictable accuracy. Even with only routine calibration, the absolute accuracy of the APCT-3 is better than $\pm 0.05^{\circ} \mathrm{C}$, surpassing the accuracy of data measured with the previous APCT tool. Because of the excellent signal to noise ratio of the APCT- 3 tool, it will be possible to achieve an absolute accuracy that is on the order of its temperature resolution, which is in the range of $0.5-2.5 \mathrm{mK}$, depending on the temperature. In addition to improved accuracy, the tool provides an order of magnitude increase in the possible sampling rate. Whereas the increased temperature resolution is necessary to resolve the small temperature changes at the end of the decay of frictional heat, the APCT-3's short sampling interval of $1 \mathrm{~s}$ is needed to capture the rapid temperature changes that occur while the coring shoe is driven into the formation.

Unfortunately, the order of magnitude increase in resolution and accuracy of the temperature data does not necessarily lead to significant improvement in estimates of undisturbed formation temperature. These estimates depend, in large part, on the algorithm that is used to extrapolate the observed transient temperature decay to steady state. The most important deficiency of the currently used TFit algorithm is the simplified nature of the one-dimensional analytical model used to calculate the reference curves to which the measured data are compared. Considerable modeling and analysis of the tool's thermal response is under way. This information will be used to evaluate uncertainties in extrapolated temperatures and to improve standard processing procedures. Since all tools used to measure formation temperature or pore pressure generate a similar transient disturbance, we hope that the processing procedures of other tools will benefit from the analysis of the APCT-3 data. This will be a valuable contribution because the extrapolation of the decay in temperature or pressure to undisturbed formation state needs standardization to allow comparison of data sets (Flemings et al., 2004).

\section{Acknowledgments}

This research was supported by German Science Foundation (DFG) Grants Vi 133/9-1 and Vi 133/9-2,
U.S. National Science Foundation (NSF) Grant OCE0326699 to University of California, Santa Cruz (A.T.F.), and Joint Oceanographic Institutions/IODP (A.M.T.). The authors benefited enormously from the guidance provided by engineering, operations, and technical support personnel of the IODP-United States Implementing Organization (USIO) Science Operator at Texas A\&M University. In particular, Peter Kannberg, Mike Meiring, and Randy Gjesvold went out of their way to accommodate this new addition to the pool of downhole tools for Expedition 311. We also thank the captain and the crew of the JOIDES Resolution, without whom this research would not have been possible. Robert Collier helped with the calibration tests in the temperature controlled tank at Oregon State University.

\section{References}

Bennett, A.S., 1972. The calibration of thermistors over the temperature range 0-30 ${ }^{\circ} \mathrm{C}$. Deep-Sea Res., 19:157-163.

Bullard, E.C., 1954. The flow of heat through the floor of the Atlantic Ocean. Proc. R. Soc. London, Ser. A, 222:408429.

Carslaw, H.S., and Jaeger, J.C., 1959. Conduction of Heat in Solids (2nd ed.): Oxford (Clarendon Press).

Davis, E.E., Villinger, H., MacDonald, R.D., Meldrum, R.D., and Grigel, J., 1997. A robust rapid-response probe for measuring bottom-hole temperatures in deep-ocean boreholes. Mar. Geophys. Res., 19:267-281. doi:10.1023/ A:1004292930361

Erikson, A., von Herzen, R., Sclater, J., Girdler, R., Marshall, B., and Hyndman, R., 1975. Geothermal measurements in deep-sea drill holes. J. Geophys. Res., 80:2515-2528.

Fisher, A.T., and Becker, K., 1993. A guide to ODP tools for downhole measurements. ODP Tech. Note, 10.

Flemings, P., Murray, R., and Fisher, A., 2004. Workshop report: downhole tools in the IODP: achieving critical goals of scientific ocean drilling. Available from the World Wide Web: http://www.usssp-iodp.org/PDFs/ DHT_Workshop_Final.pdf.

Heesemann, M., Villinger, H., Jannasch, H.W., Kastner, M., and the Expedition 301T Scientists, 2006. Data report: Long-term temperature measurements in Holes 1253A and 1255A off Costa Rica, ODP Leg 205. In Morris, J.M., Villinger, H.W., and Klaus, A. (Eds.), Proc. ODP, Sci.

Results, 205 [Online]. Available from World Wide Web: http://www-odp. tamu.edu/publications/205_SR/ 209/209.htm.

Horai, K., 1985. A theory of processing down-hole temperature data taken by the hydraulic piston corer (HPC) of the DSDP. Tech. rep., Lamont-Doherty Geological Observatory, Palisades, NY.

Horai, K., and Von Herzen, R.P., 1985. Measurement of heat flow on Leg 86 of the Deep Sea Drilling Project. In Heath, G.R., Burckle, L.H., et al., Init. Repts. DSDP, 86: Washington (U.S. Govt. Printing Office), 759-777. 
Hyndman, R.D., Langseth, M.G., and Von Herzen, R.P., 1987. Deep Sea Drilling Project geothermal measurements: a review. Rev. Geophys., 25:1563-1582.

Jannasch, H., Davis, E., Kastner, M., Morris, J., Pettigrew, T., Plant, J.N., Solomon, E., Villinger, H., and Wheat, C.G., 2003. CORK-II: long-term monitoring of fluid chemistry, fluxes, and hydrology in instrumented boreholes at the Costa Rica subduction zone. In Morris, J.D., Villinger, H.W., Klaus, A., Proc. ODP, Init. Repts., 205 [Online]. Available from World Wide Web: http:// www-odp.tamu.edu/publications/205_IR/chap_02/ chap_02.htm.

Kappel, E., and Adams, J. (Eds.), 2001. Earth, Oceans and Life: Scientific Investigation of the Earth System Using Multiple Drilling Platforms and New Technologies-Integrated Ocean Drilling Program Initial Science Plan, 2003-2013: Washington, D.C. (International Working Group Support Office).

Pfender, M., and Villinger, H., 2002. Miniaturized data loggers for deep sea sediment temperature gradient measurements. Mar. Geol., 186:557-570. doi:10.1016/ S0025-3227(02)00213-X

Pribnow, D.F.C., Kinoshita, M., and Stein, C.A., 2000. Thermal data collection and heat flow recalculations for ODP Legs 101-180. Institute for Joint Geoscientific Research, GGA, Hanover, Germany, 0120432. Available from World Wide Web: http://www-odp.tamu.edu/ publications/heatflow/ODPReprt.pdf.

Shipboard Scientific Party, 1992. Explanatory notes. In Davis, E.E., Mottl, M.J., Fisher, A.T., et al., Proc. ODP, Init. Repts., 139: College Station, TX (Ocean Drilling Program), 55-97.
Shipboard Scientific Party, 1997. Rough basement transect (Sites 1026 and 1027). In Davis, E.E., Fisher, A.T., Firth, J.V., et al., Proc. ODP, Init. Repts., 168: College Station, TX (Ocean Drilling Program), 101-160. [PDF]

Steinhart, J.S., and Hart, S.R., 1968. Calibration curves for thermistors. Deep-Sea Res., 15:497-503.

Uyeda, S., and Horai, K., 1982. Heat flow measurements on Deep Sea Drilling Project Leg 60. In Hussong, D.M., Uyeda, S., et al., Init. Repts. DSDP, 60: Washington (U.S. Govt. Printing Office), 789-800.

Von Herzen, R.P., and Maxwell, A.E., 1964. Measurement of heat flow at the preliminary Mohole site off Mexico. J. Geophys. Res., 69:741-748.

Publication: 28 October 2006

MS 311-108

\section{Appendix}

Temperature data of the preliminary APCT-3 calibration (Fig. F4) and the response to sudden temperature change (Fig. F6) will be submitted to the IODP-USIO database. The APCT-3 data (CALIBRAT.DAT and RESPONSE.DAT in "Supplementary Material") are provided in the WinTemp ASCII format described in "Tool description." Calibration reference temperatures (APC3CALB.LOG in "Supplementary Material") are only given at times when the bath temperature was close to one of the five temperature holding points. Holding times are given in separate header lines before and after the temperature data of a holding point. 
Figure F1. A. Mechanical design of the APC cutting shoe. B. APCT-3 electronics mounted on a cylindrical frame that fits the annular cavity of the cutting shoe.

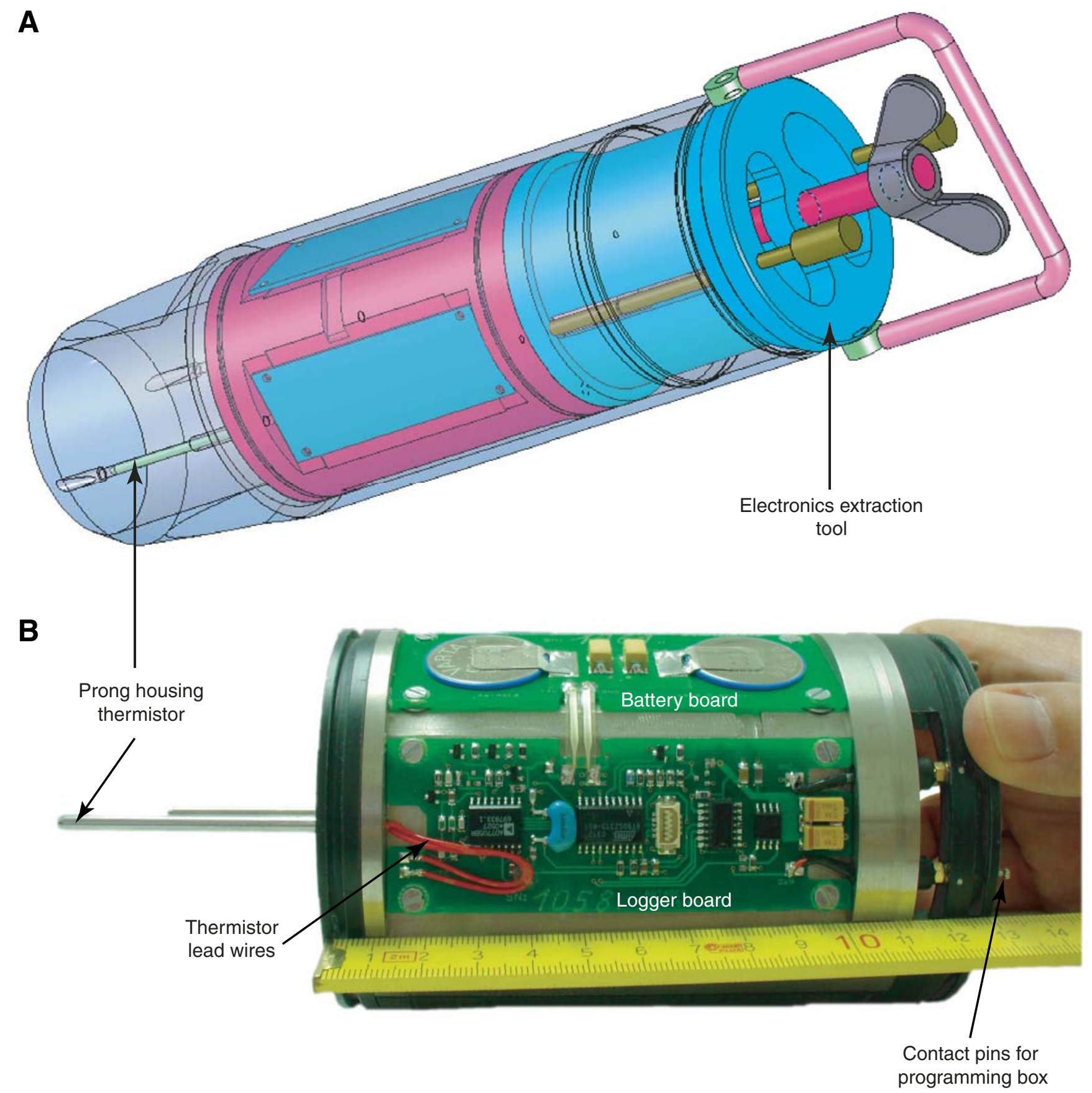


Figure F2. (A) Logger readings, (B) thermistor resistances, and (C) temperature resolution over the whole temperature measurement range of the APCT-3 prototype used during Expedition 311.
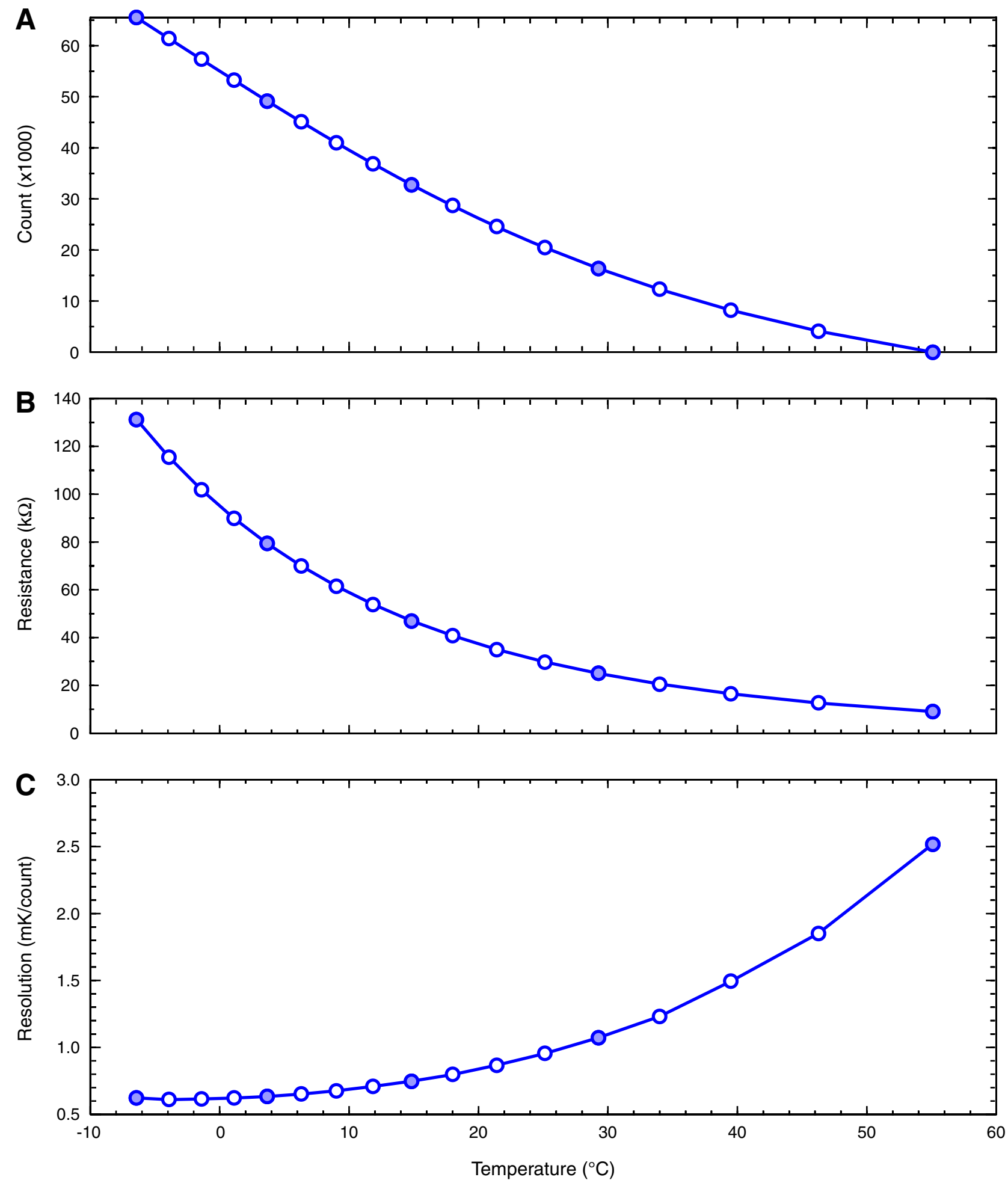
Figure F3. Expected quality of a three-point Steinhart-Hart calibration over the complete temperature measurement range of the APCT-3. A. Nominal thermistor characteristics provided by the manufacturer and Steinhart-Hart prediction based on three calibration points. B. Difference between nominal characteristics and prediction.
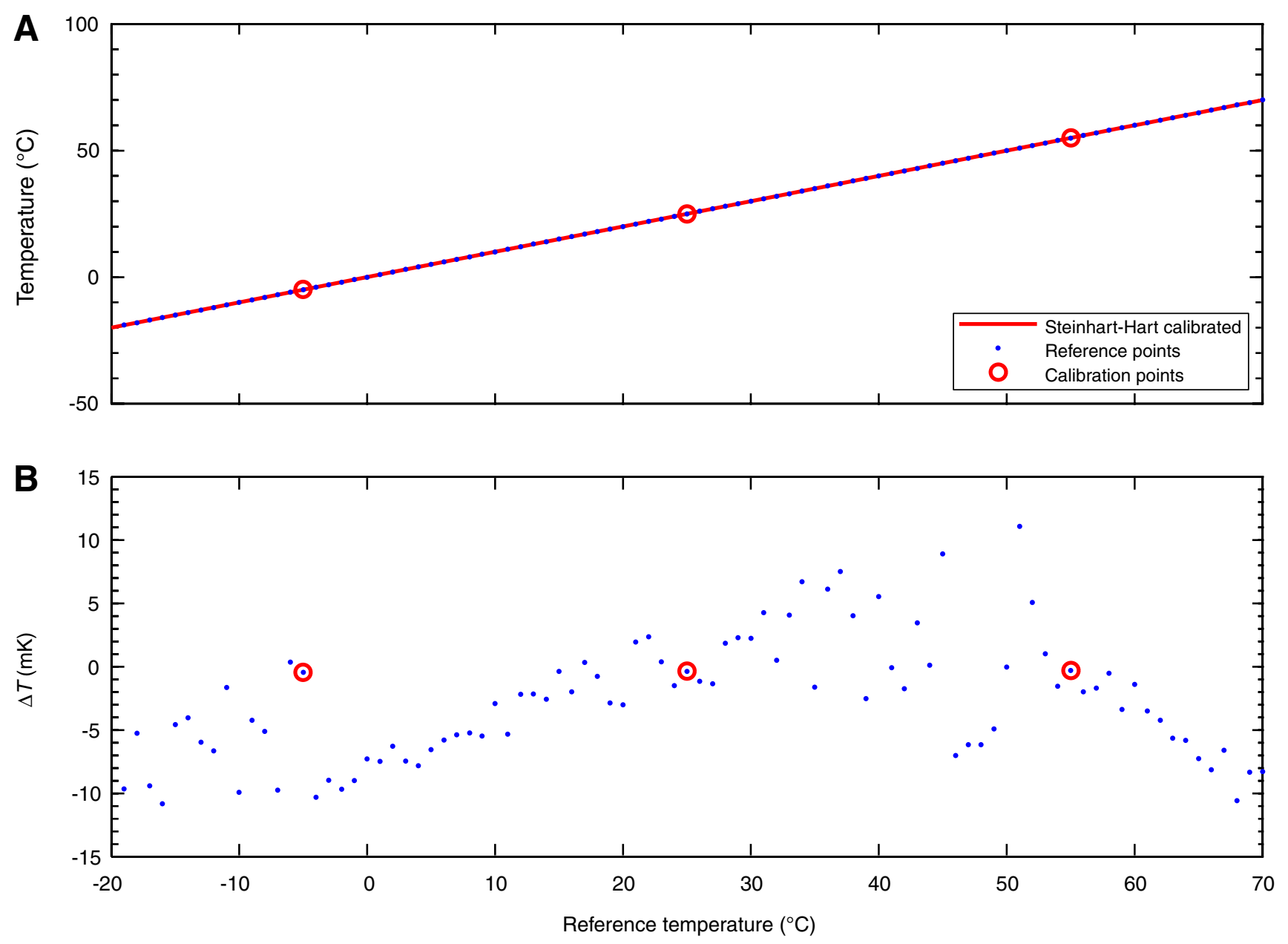
Figure F4. Preliminary APCT-3 calibration. A. Uncalibrated third-generation advanced piston corer temperature (APCT-3; APC3 in figure) tool temperatures and reference temperatures during calibration in well-stirred bath. B. Differences between reference and APCT-3 temperatures. C. Linear regression of temperature differences and reference temperatures. D. Reference temperatures as a function of thermistor resistivity (blue dots) and best fitting Steinhart-Hart parametrization. E, F. Differences between reference temperatures and APCT-3 temperatures computed with best fitting Steinhart-Hart approximation (cf. D).
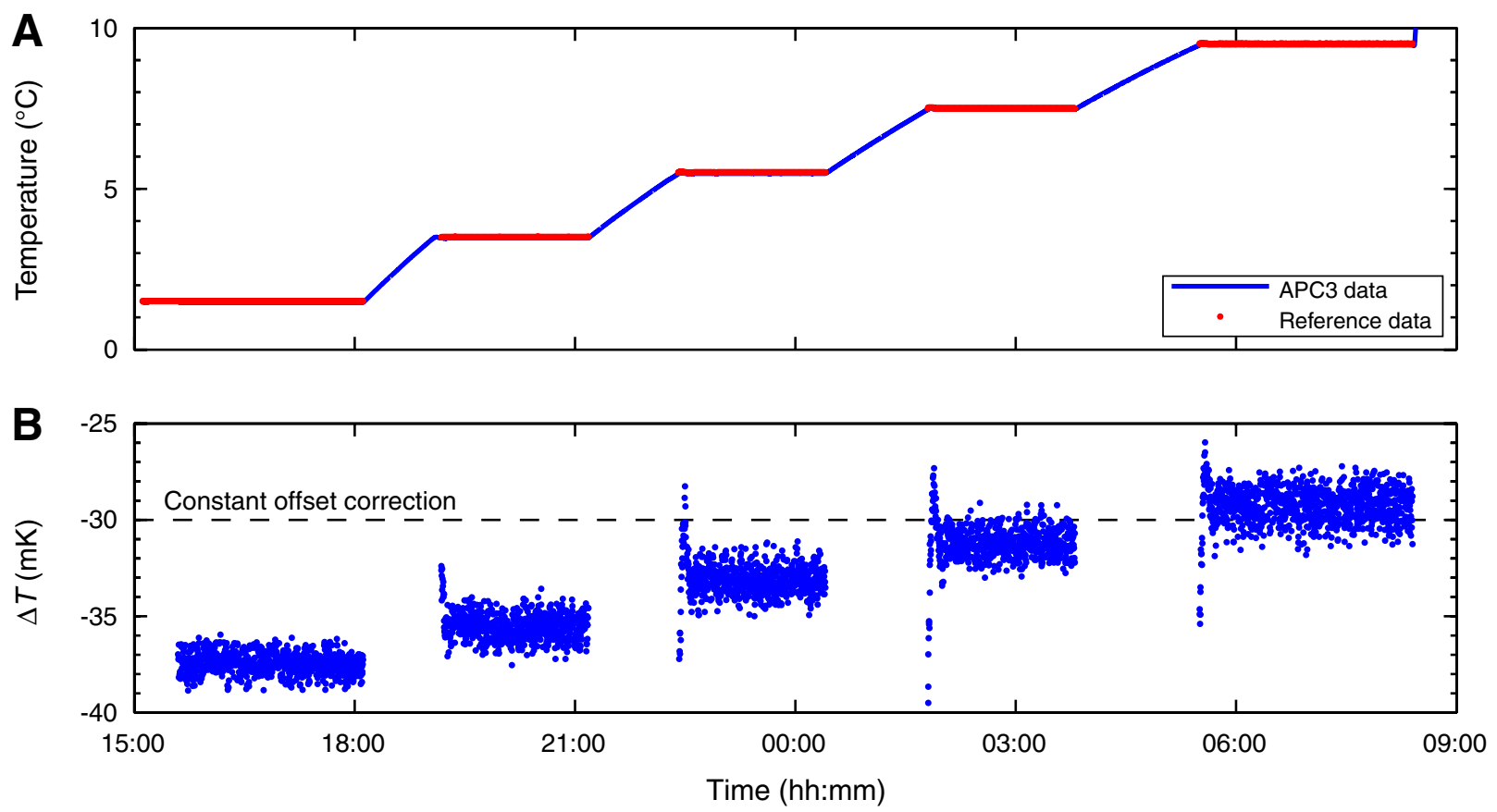

C

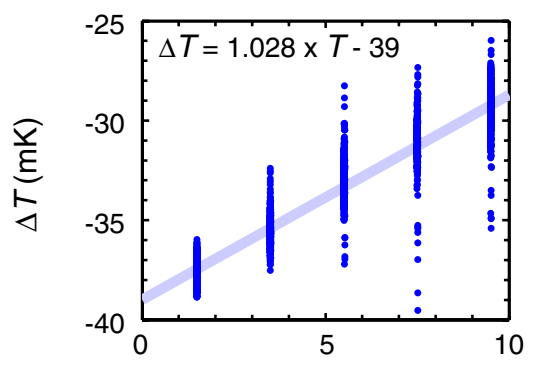

Ref. temperature $\left({ }^{\circ} \mathrm{C}\right)$
D

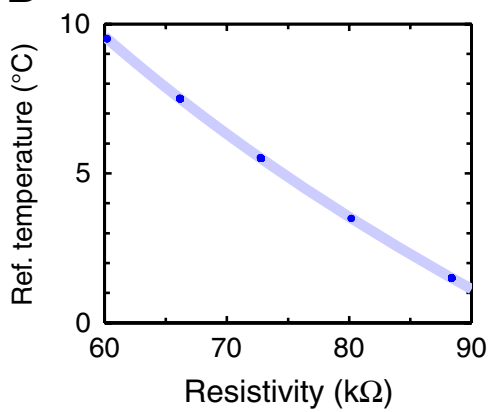

E

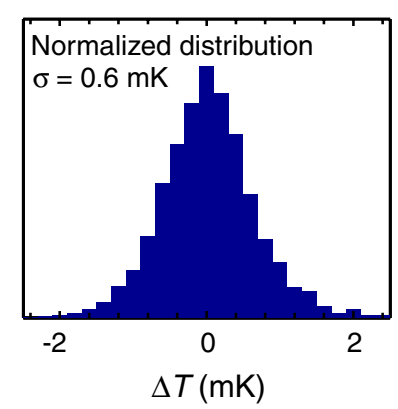

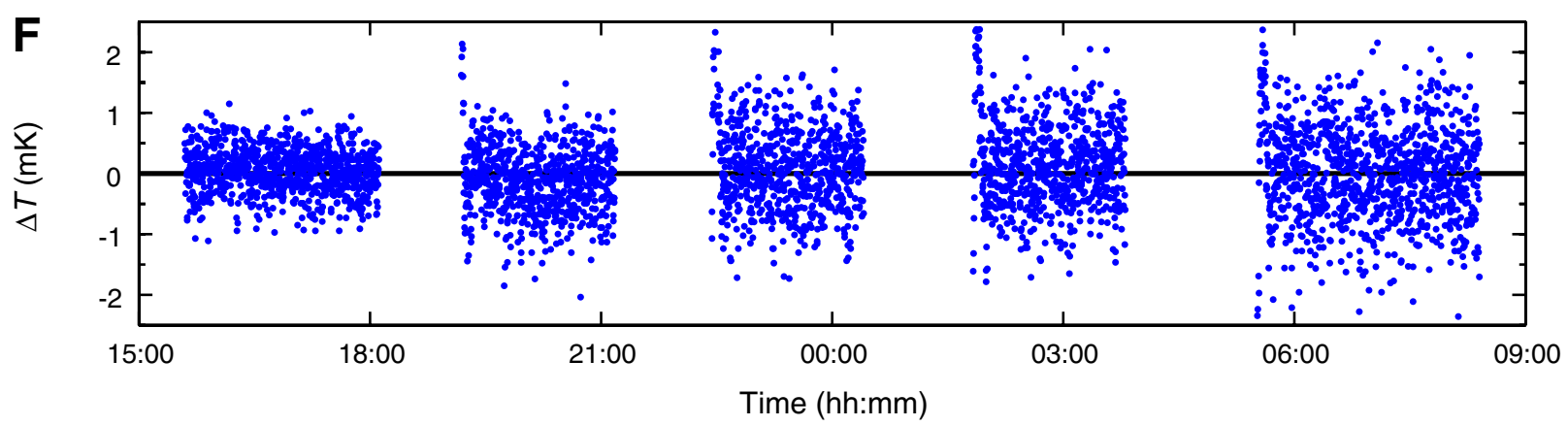


Figure F5. (A) Steinhart-Hart calibrated third-generation advanced piston corer temperature (APCT-3; APC3 in figure) tool temperature data and calibration bath reference temperatures demonstrates that (B) temperature differences remain on the order of $\pm 1 \mathrm{mK}$ even during minor temperature excursions.
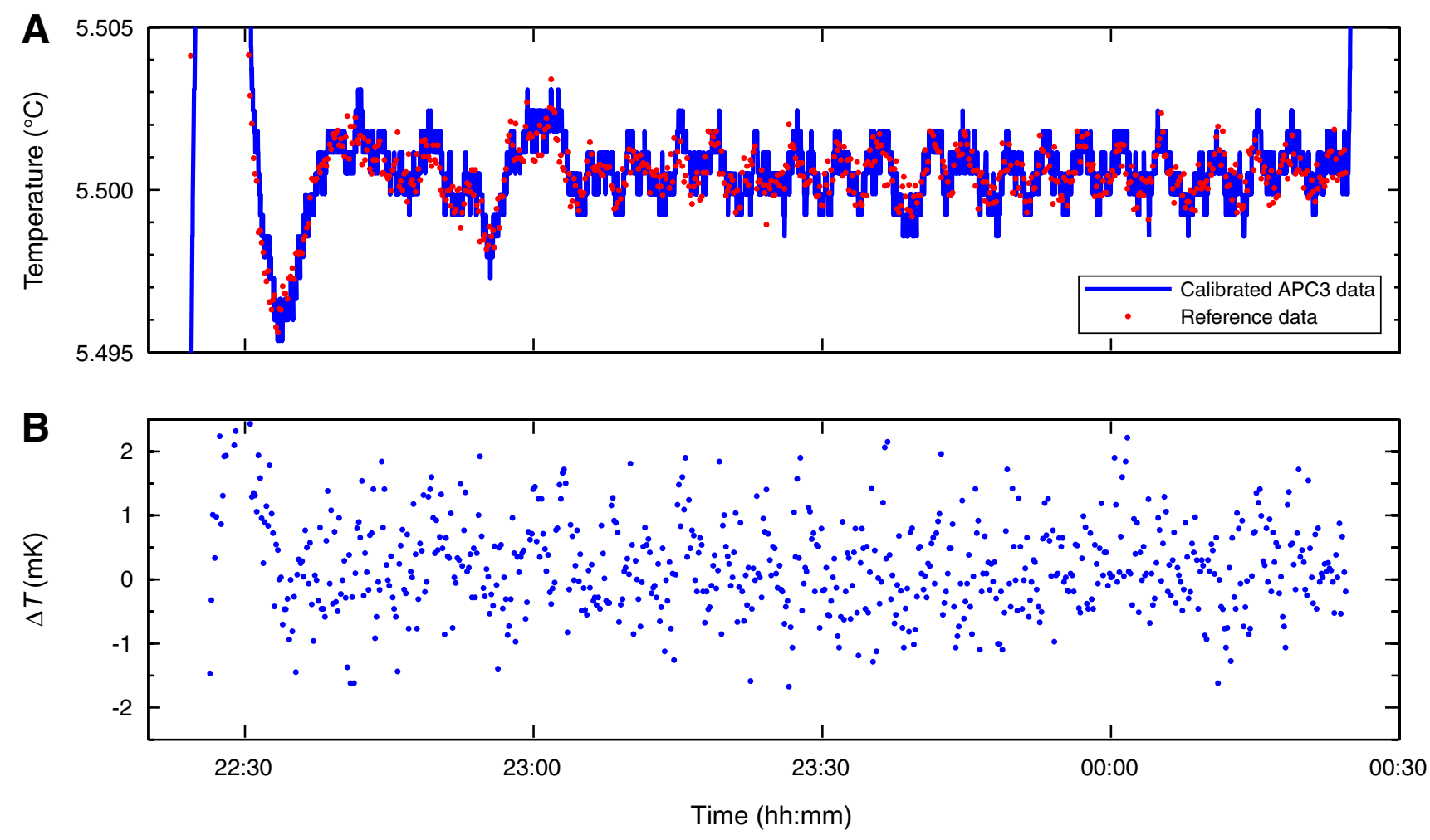
Figure F6. A. To determine the APCT-3 response to sudden temperature change, the tool was alternately submerged in cold and warm water. B. Comparison of three normalized temperature transients with an exponential decay function) indicates that the APCT-3 thermal time constant is $\sim 10 \mathrm{~s}$.
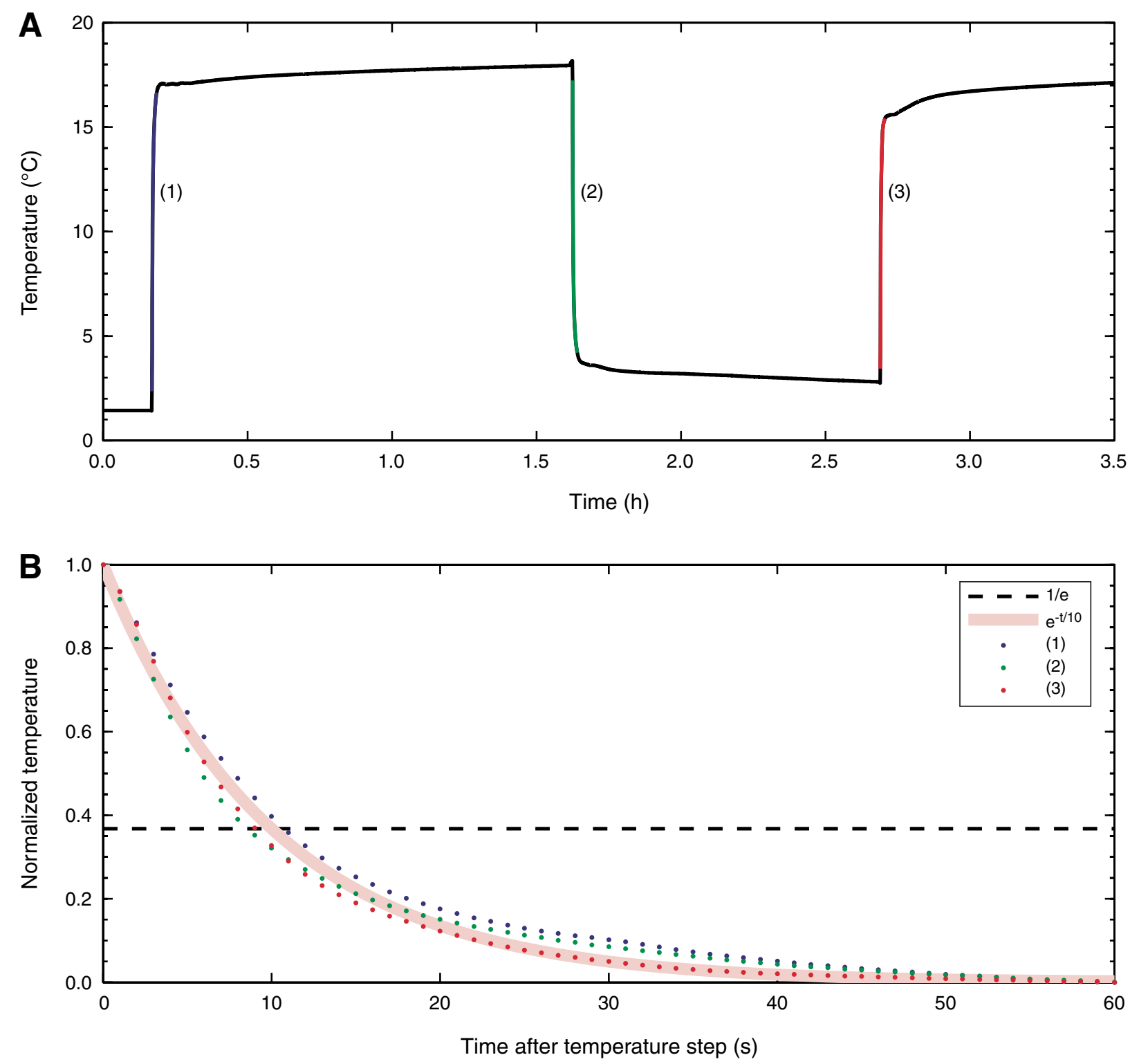
Figure F7. A. Complete temperature record of a typical APCT-3 deployment. B-E. Details of some important stages of deployment at differing time and temperature scales.
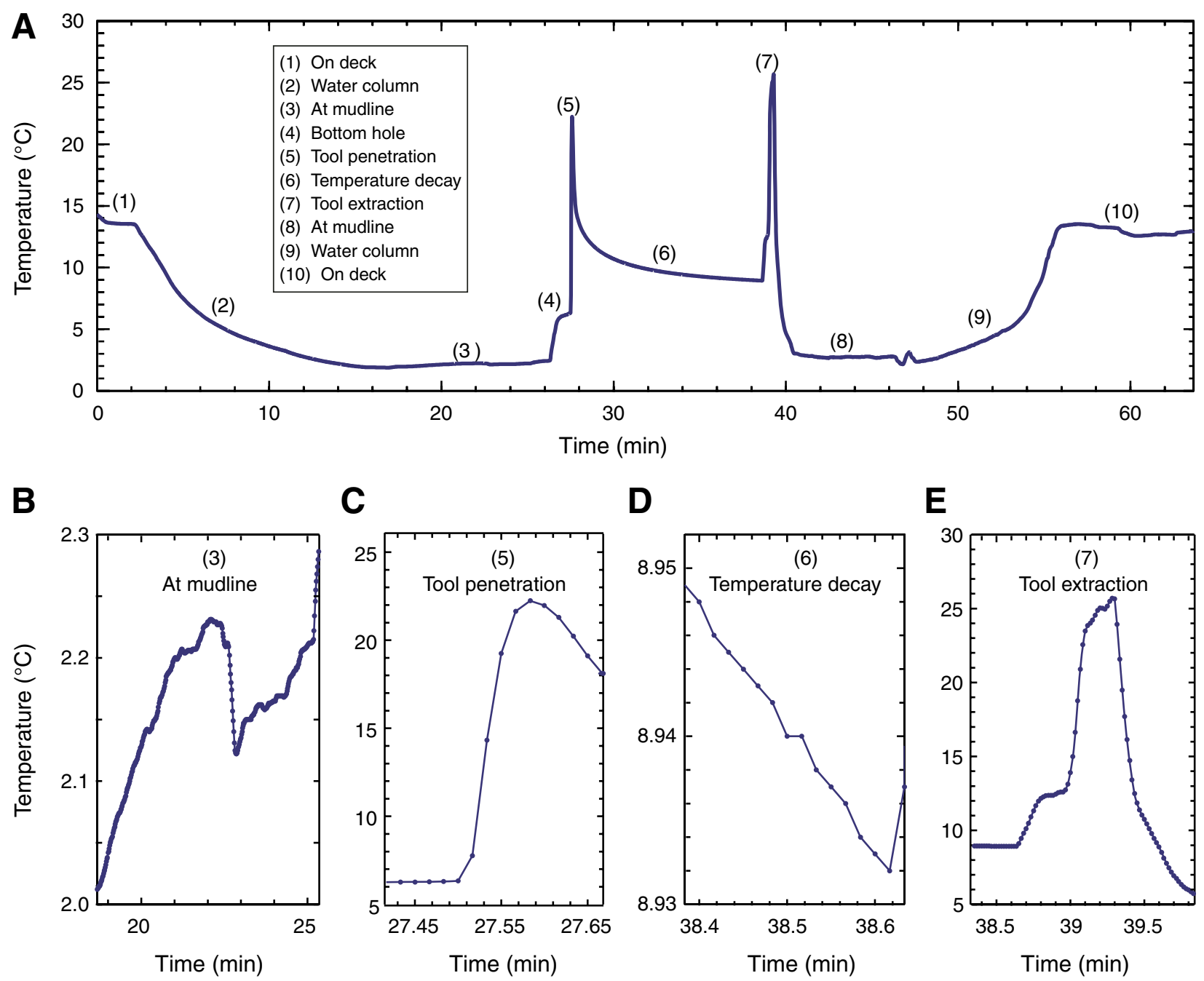
Figure F8. A. Comparison of temperature data measured at Site U1329 using the APCT (Core 311-U1329C$11 \mathrm{H}$; red) and the APCT-3 (Core 311-U1329C-13H; blue). The dashed lines show the extrapolated undisturbed formation temperatures at 95.6 and 114.6 mbsf, respectively, using TFit. B. Derivative with respect to time of APCT-3 data showing the temperature resolution that is required to resolve a typical decay curve.
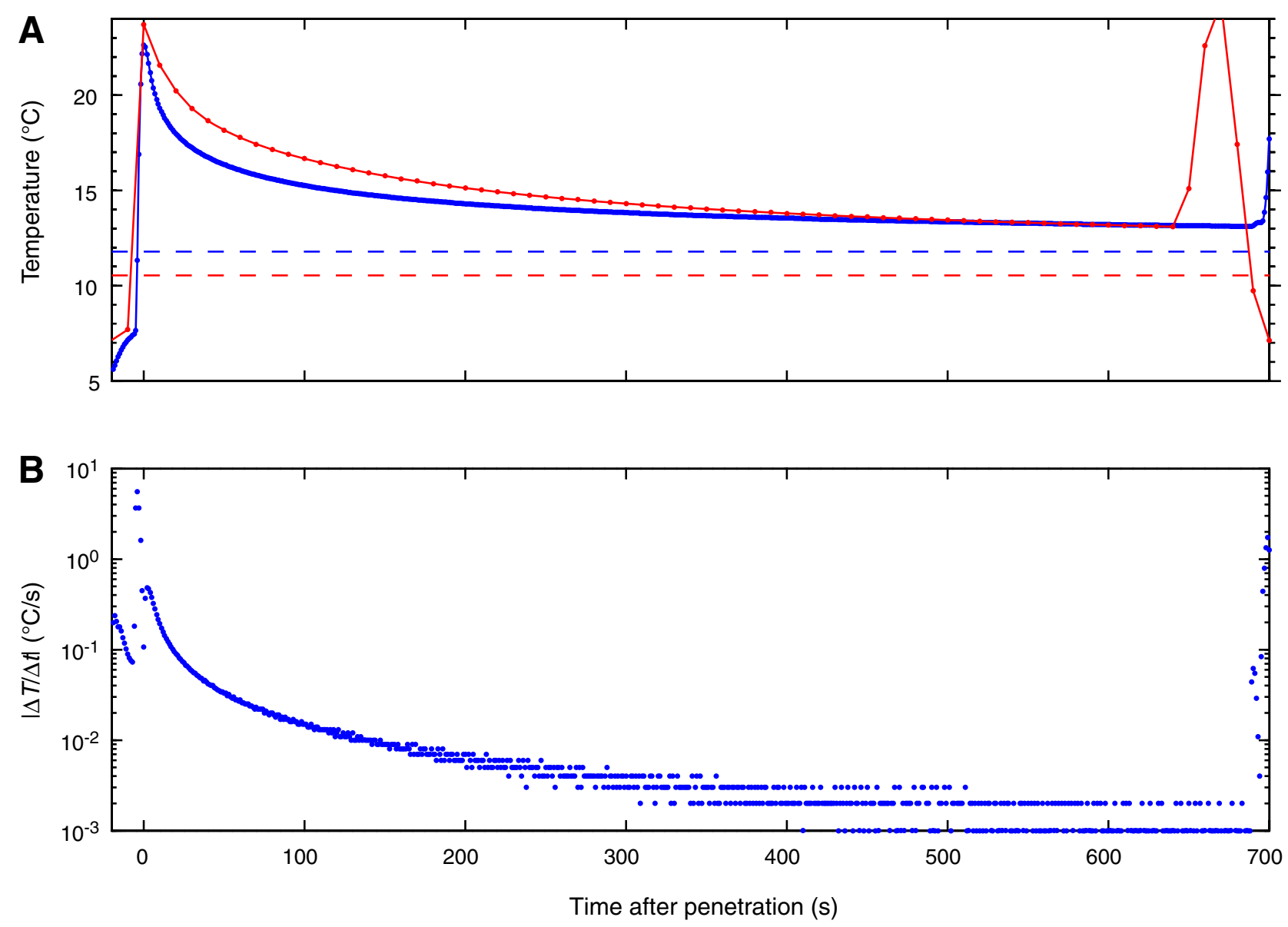
Figure F9. A-C. APCT-3 data (Core 311-U1329C-13H; white dots on blue line) compared to hypothetical data measured using a reduced sampling interval of 10 s. D. APCT data (Core 311-U1329C-11H).
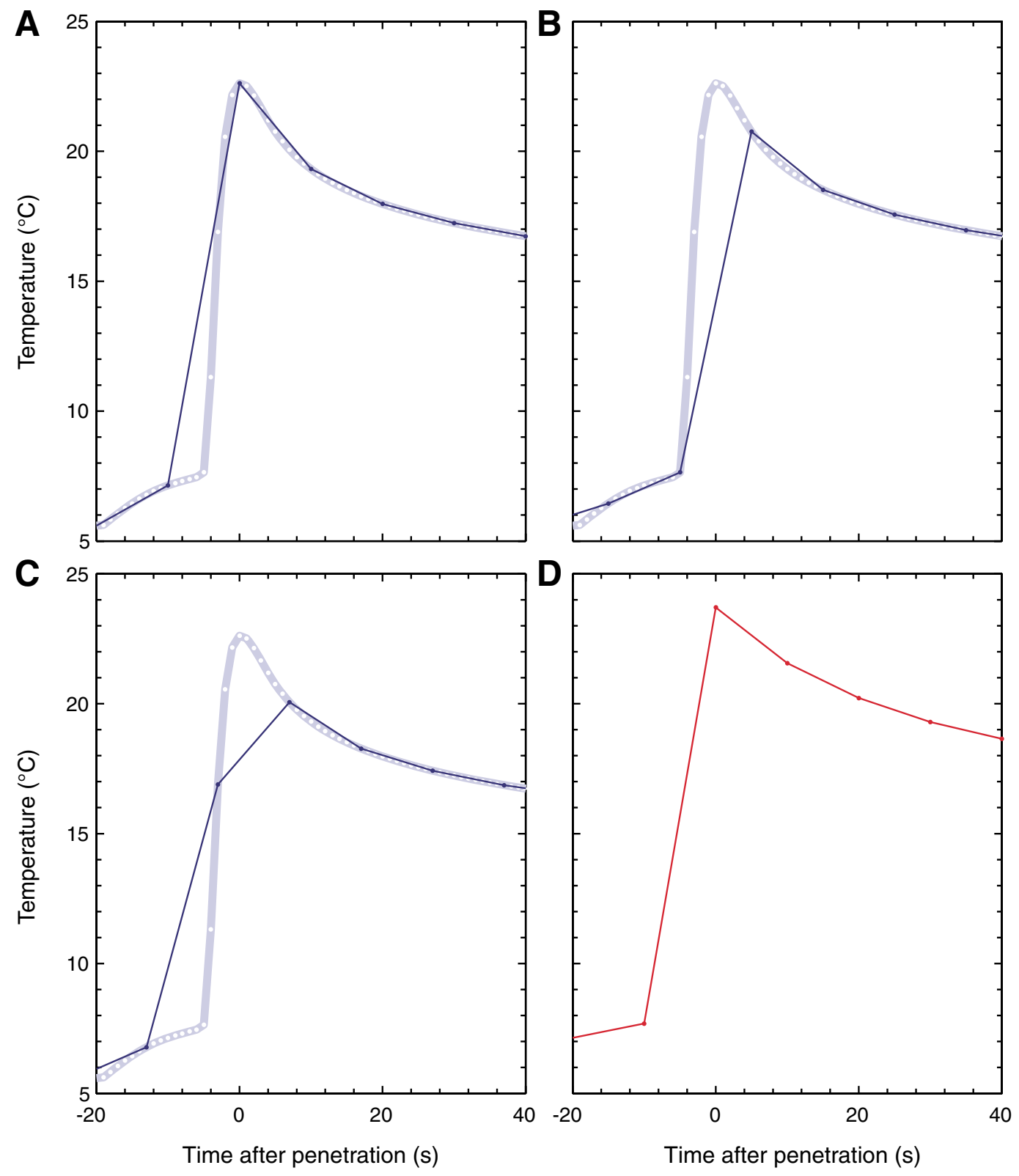
Figure F10. A. Estimated undisturbed formation temperatures measured at Site U1329. The advanced piston corer temperature (APCT) tool measurement at $33.5 \mathrm{mbsf}$, disturbed by heave, is neglected in the computation of the linear regression and the confidence interval area. APCT-3 = third-generation advanced piston corer temperature tool, DVTP = Davis-Villinger Temperature Probe. B. Thermal conductivity measurements of Site U1329 core material.

A

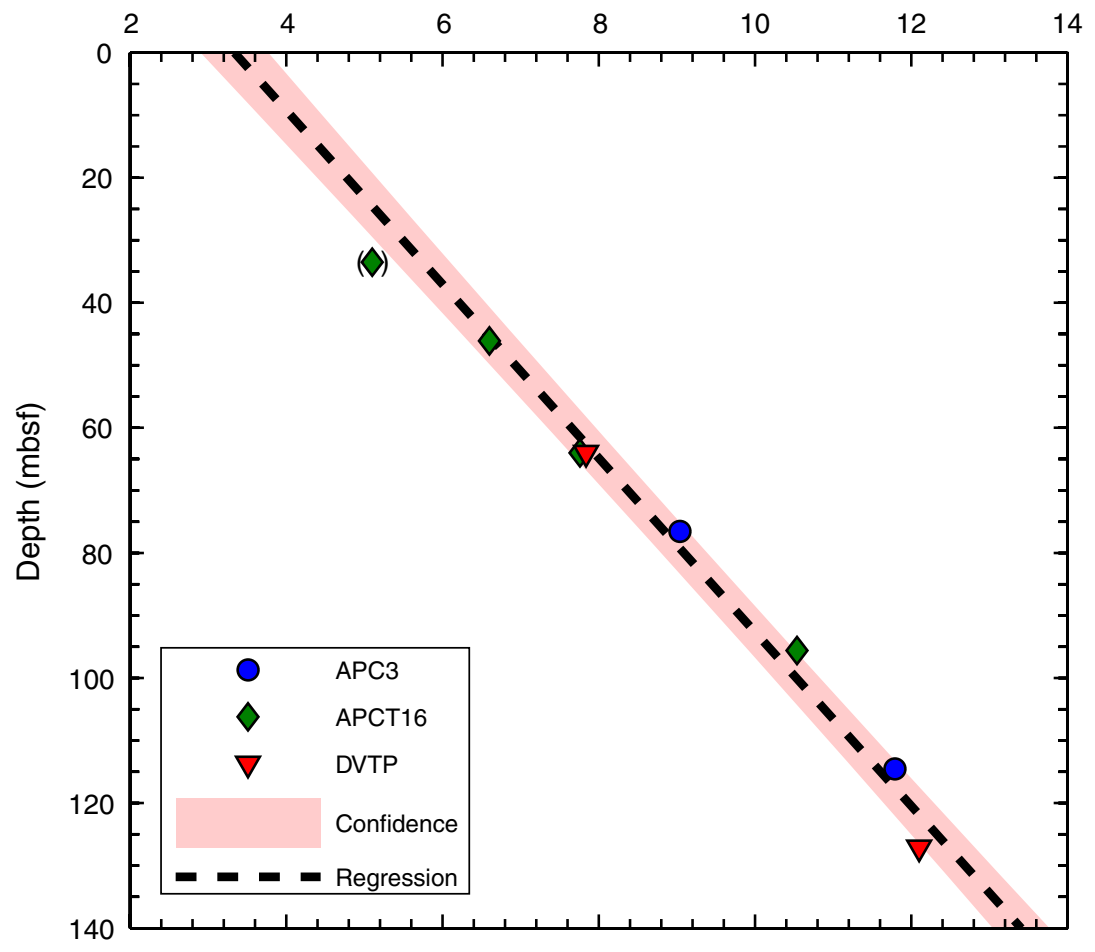

B Thermal conductivity $(\mathrm{W} /[\mathrm{m} \cdot \mathrm{K}])$

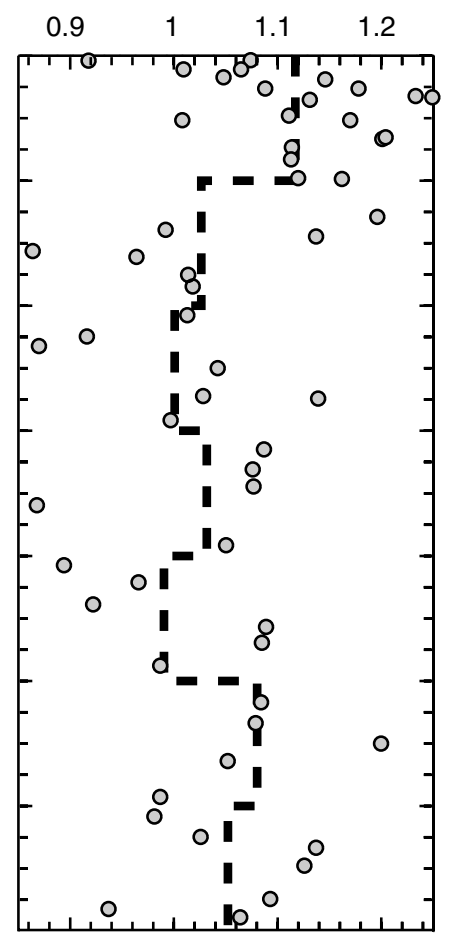


Table T1. Calibration constants.

\begin{tabular}{lcl}
\hline Constant & \multicolumn{1}{c}{ Value } & \multicolumn{1}{c}{ Unit } \\
\hline $\mathrm{b}$ & 11899.26821 & None (digital counts) \\
$\mathrm{m}$ & 90961.56387 & Ohm \\
$\mathrm{A}_{1}$ & 0.000936864596 & $1 /$ Kelvin \\
$\mathrm{A}_{2}$ & 0.000221013193 & $1 /$ Kelvin \\
$\mathrm{A}_{3}$ & 0.000000126511 & $1 /$ Kelvin \\
\hline
\end{tabular}

Note: For Equations E1 and E2 based on preliminary APCT-3 calibration. 